\title{
A case of penile gangrene
}

\author{
Irina Brennan ${ }^{1}$, Lars K. Beattie ${ }^{2^{*}}$, Brandon Allen ${ }^{2}$, Bobby Desai ${ }^{2}$ \\ ${ }^{1}$ University of Florida, Gainesville, USA; \\ ${ }^{2}$ Department of Emergency Medicine, University of Florida College of Medicine, Gainesville, USA; \\ *Corresponding Author: bdesai@ufl.edu
}

Received 28 August 2013; revised 30 September 2013; accepted 20 October 2013

Copyright (c) 2013 Bobby Desai et al. This is an open access article distributed under the Creative Commons Attribution License, which permits unrestricted use, distribution, and reproduction in any medium, provided the original work is properly cited.

\section{ABSTRACT}

Penile gangrene is a rare entity and is usually associated with significant trauma. We report on a self-inflicted cause of penile gangrene in a patient who sought enhancement.

\section{Keywords: Penis; Gangrene; Enhancement}

\section{INTRODUCTION}

Penile modification is done for many reasons, includeing peer pressure, enhancement of penile girth and length, and for a perceived increase in female pleasure [1]. There can be significant complications of modification, from the urethral injury, to penile abscesses. Late complications of modifications include chronic pain and erectile dysfunction [2]. Penile modification is becoming more commonplace in the United States [2].

\section{CASE}

A 55-year-old man with no significant past medical history presented to the emergency department with the waiting room triage complaint of priapism. He reported progressive worsening of penile pain and swelling for three weeks after an attempt at male enhancement at home. The patient had no difficulty with urination and denied fevers or chills. His review of systems was noncontributory. On physical examination, his vital signs were normal, with no fever. His cardiac, respiratory, abdominal and neurologic exam was normal. On physical examination of his inguinal and genital area, a foulsmelling, poikilothermic, edematous and insensate penis along the entire corpus and glans was revealed (Figure 1), along with a weight inserted over the penis (Figure 2).

Urology was consulted to see the patient. The patient underwent immediate penile exploration and operative foreign body removal. The initial procedure was followed by tissue removal to the Buck's fascia with bilateral corpora cavernosa reconstruction and skin graft-

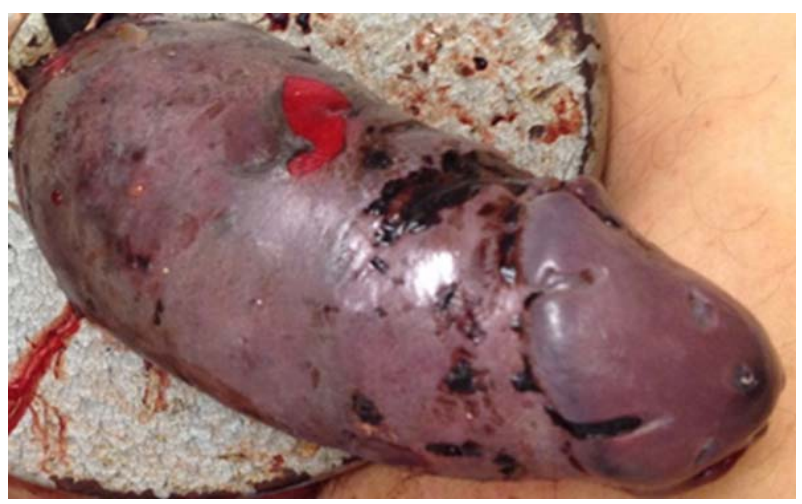

Figure 1. Patient's genital region on presentation to the emergency department demonstrated priapism and necrosis.

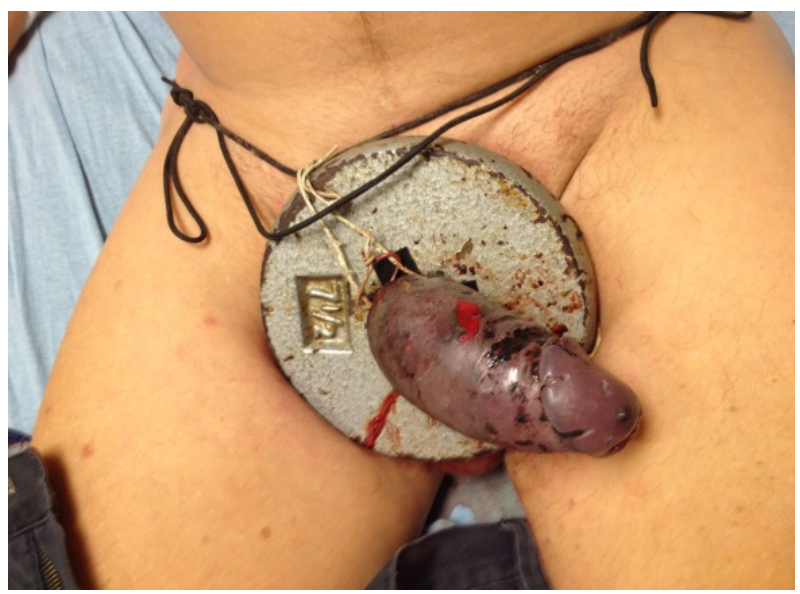

Figure 2. Patient's genitalia with the encompassing $7.5 \mathrm{l} b$ free weight attached to his waist with a combination of strings and wire.

ing of the glans and penile shaft. The patient's psychiatric evaluation was significant for poor insight and mild developmental delay.

\section{DISCUSSION}

Penile gangrene is secondary to incarceration by a 
foreign object. The patient placed $7.51 \mathrm{~b}$ free weight around the base of his penis for "penile enlargement" (see Figure 2) but was subsequently unable to remove it secondary to edema. Penile strangulation was first reported in 1755. Accounts in medical literature have placed around the penis since described various metallic and nonmetallic objects, mostly for autoerotic or performance enhancement purposes. The time from incarceration to require medical attention can range from hours to weeks and directly correlates with hospital stay $[3,4]$. Complications vary from mild vascular obstruction, urethral strictures and fistulas to severe gangrene, septic shock and death [5]. The treatment priority is detumescence to facilitate blood flow and urination. Penile amputation may be necessary in cases of severe injury [6].

\section{REFERENCES}

[1] Thomson, N., et al. (2008) Penile modification in young Thai men: Risk environments, procedures and widespread implications for HIV and sexually transmitted infections. Sexually Transmitted Infections, 84, 195-197. http://dx.doi.org/10.1136/sti.2007.028530

[2] Nguyen, D.P., Bobby, K.D. and Michael, F. (2011) Visual Diagnosis: Pearling: A case study. International Journal of Emergency Medicine, 8, 1-3.

[3] Detweiler, M. (2001) Penile incarceration with metal objects:
A review of procedure choice based on penile trauma grade. Scandinavian Journal of Urology and Nephrology, 35, 212-217. http://dx.doi.org/10.1080/003655901750291980

[4] Xu, T., Gu, M. and Wang, H. (2009) Emergency management of penile strangulation: A case report and review of the Chinese literature. Emergency Medicine Journal, 26, 73-74. http://dx.doi.org/10.1136/emj.2008.062877

[5] Morentin, B., Biritxinaga, B. and Crespo, L. (2011) Penile strangulation: Report of a fatal case. The American Journal of Forensic Medicine and Pathology, 32, 344346. http://dx.doi.org/10.1097/PAF.0b013e3181d8e3a5

[6] Bart, S., Culty, T., Pizzoferrato, A.C., Thibault, F., Girault, N., Chartier-Kastler, E. and Richard, F. (2008) Complete necrosis of the penis and testes by strangulation in a psychotic patient. Progrès en Urologie, 18, 483-485. http://dx.doi.org/10.1016/j.purol.2008.04.014 